\title{
Article \\ Effect of Ozone Treatment on the Properties of Oil Palm Empty Fruit Bunch Sulfonated Chemi-Mechanical Pulp
}

\author{
Xing Wan (1), Yang Ping and Jun $\mathrm{Li}^{*}$ \\ State Key Laboratory of Pulp and Paper Engineering, South China University of Technology, \\ Guangzhou 510641, China; 201820126093@mail.scut.edu.cn (X.W.); 201910105509@mail.scut.edu.cn (Y.P.) \\ * Correspondence: ppjunli@scut.edu.cn
}

check for updates

Citation: Wan, X.; Ping, Y.; Li, J.

Effect of Ozone Treatment on the Properties of Oil Palm Empty Fruit Bunch Sulfonated Chemi-Mechanical Pulp. Forests 2021, 12, 1085. https://doi.org/10.3390/f12081085

Academic Editors: Duarte M. Neiva and Solange Araújo

Received: 14 July 2021

Accepted: 11 August 2021

Published: 13 August 2021

Publisher's Note: MDPI stays neutral with regard to jurisdictional claims in published maps and institutional affiliations.

Copyright: (c) 2021 by the authors. Licensee MDPI, Basel, Switzerland. This article is an open access article distributed under the terms and conditions of the Creative Commons Attribution (CC BY) license (https:// creativecommons.org/licenses/by/ $4.0 /)$.

\begin{abstract}
Oil palm empty fruit bunch (EFB) as an abundant waste material can be utilized for pulp production to alleviate the shortage of raw materials in the paper industry. Sulfonated chemimechanical pulp (SCMP) has great potential in paper making industry. However, its poor performance due to the high surface lignin content limits its application. In this study, we used EFB as raw material to produce SCMP and systematically studied the effect of ozone treatment on pulp properties. Results show that the surface structure and morphology of fibers exhibited distinct differences under different ozone dosage treatments. Compared to the control, the content of surface lignin of pulps was reduced by $2.56 \%, 4.64 \%, 13.24 \%$ and $25.24 \%$ when ozone consumption was $1,3,5$ and $7 \mathrm{wt} \%$, respectively. Meanwhile, the treated pulp had a lower drainability at the same refining energy level. Moreover, the physical and optical properties of handsheets were improved significantly after ozone treatment. Ozone treatment is a very efficient way to improve the performance of SCMP. Additionally, this method avoids complicated processes and chemical consumption. Therefore, as an effective, environmentally friendly and low-cost treatment method, ozone treatment can improve the performance of EFB SCMP and thus provide a high-quality pulp resource.
\end{abstract}

Keywords: oil palm empty fruit bunch; ozone; sulfonated chemi-mechanical pulp; surface lignin

\section{Introduction}

In recent years, a series of policies and regulations have been issued in response to deteriorating environmental problems caused by the extensive utilization of wood in pulp and papermaking. Meanwhile, the global consumption and demand for paper products are still growing rapidly. The shortage of raw materials has become an urgent situation that the world's pulp and paper industry is facing [1]. Forests provide more than $80 \%$ of pulp's raw materials, which can result in massive and unsustainable deforestation leading to the destruction of ecosystems and causing environmental problems [2]. The pulp and paper industry has been looking for new raw materials to replace wood, especially in some woodscarce countries. Various bioresources such as sugar bagasse, rice straw, wheat straw and palm oil empty fruit have been evaluated to assess their potential as raw materials for the papermaking industry [3,4]. Oil palm empty fruit bunches (EFBs) are the main industrial waste from palm oil, which is widely distributed in Malaysia, Indonesia, Thailand, etc. [5]. Currently, the EFB is commonly treated by direct incineration; however, this treatment not only damages the environment but also is a waste of resources. Therefore, the effective utilization of EFB for pulp and papermaking can alleviate the shortage of pulping raw materials.

Although various chemical pulping methods have been reported, environmentally friendly and low-cost methods are still lacking for EFB application. Mechanical pulping can maximize the yield with lower production costs while maintaining a small environmental impact [6]. On the downside, the fiber binding force is not as good as with chemical pulp, leading to lower physical strength which hinders its application for several end-uses [7]. 
Chemical-mechanical pulp has the advantages of high yields, low costs and superior pulp properties [8]. Therefore, various methods have been utilized in the improvement of mechanical pulp, such as mild chemical, enzymatic and biological pretreatments [9-11]. Among these methods, sulfonation pretreatment produces $\mathrm{OH}-,-\mathrm{SO}_{3} \mathrm{H}^{-}$and $-\mathrm{SO}_{3}{ }^{2-}$ which could improve the hydrophilic properties of the raw materials and increase the water absorption and swelling properties of the fibers.

After sulfonation treatment, the flexibility and strength of mechanical pulp fibers are greatly improved. Even so, many lignins can be redeposited onto the fiber surface in the mechanical pulping process [12], since the mechanical process separates fibers mostly in the primary and middle lamella which contain a large amount of lignin [13,14]. The high amount of lignin on the fiber surface will not only form a physical barrier to block the connection between fibers but also prevent the formation of hydrogen bonds due to the hydrophobicity of lignin [15]. The removal of the lignin on the surface could expose more cellulose, which could thus enhance the physical properties of paper. Therefore, an effective method should be developed to improve the fiber surface of SCMP.

As one of the most powerful oxidizing agents, ozone gas has a strong oxidation potential of $2.07 \mathrm{eV}[16,17]$. In recent years, with the development of ozone technology and ozone generators, ozone has been increasingly used in industrial applications, mainly used in both elemental chlorine-free (ECF) and total chlorine-free (TCF) bleaching sequences [18]. Due to its powerful oxidizing properties, lignin can be degraded rapidly when in contact with ozone [19], while if in excess, ozone and radicals generated during the process may also react with carbohydrates and deteriorate the pulp quality [18]. Therefore, the ozone dosage should be controlled. On the other hand, when the lignin content of pulps is relatively high, ozone could selectively react with the lignin while the carbohydrates are well-protected $[20,21]$. Reactions between ozone and lignin are complex; ozone can react with almost all functional groups in lignin [18], including reacting with double bonds in the side chain, destroying the aromatic rings and forming carbonyl groups and peroxides [22]. Ozone treatment is qualified and feasible in terms of lignin removal, low cost and environmental friendliness [16]. Based on its properties and the effect on lignin, we could use ozone treatment to degrade the lignin on the fiber surface to improve the performance of SCMP.

Surface lignin is an important factor involved with paper performance. In this research, in order to compensate for the pulp quality problems caused by a large amount of lignin covering the fiber surface in chemical mechanical pulping, we investigated the impact of ozone treatment on degrading fiber surface lignin of EFB SCMP. As shown in Figure 1, firstly, we obtained EFB SCMP under laboratory conditions. In this case, the fiber surface is covered with high amounts of lignin, making its fibrillation in subsequent processing difficult. Then, different dosages of ozone were reacted with the obtained pulp through our self-developed ozone reaction device. The pulp fibers were completely exposed to the ozone atmosphere, and the lignin on the surface was destroyed. Finally, the fibers after different ozone dosage treatments were characterized by X-ray photoelectron spectroscopy (XPS), Fourier transform infrared spectroscopy (FT-IR), scanning electron microscope (SEM) and thermogravimetric analysis (TGA). The effect of ozone treatment was also evaluated regarding energy savings in the pulp refining process. In addition, the physical properties of the treated and untreated handsheets were evaluated for comparison. Compared with other traditional treatments, this method avoids complicated processes and chemical consumption. Thus, ozone treatment can not only reduce production costs but also effectively protect the environment. 


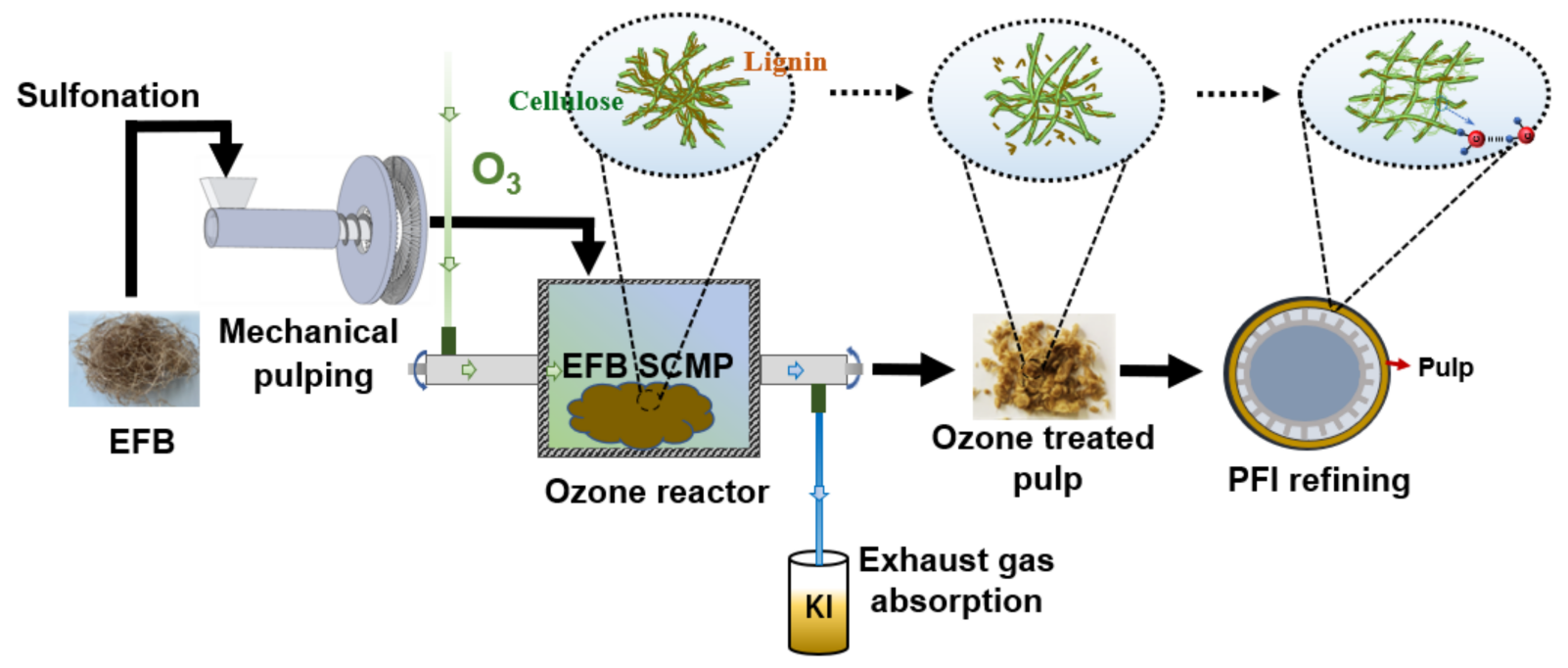

Figure 1. The schematic diagram of the EFB SCMP ozone treatment process and the fiber changes after ozone treatment.

\section{Materials and Methods}

\subsection{Materials}

EFB was supplied by Heng Huat Resources Group (Malaysia). Sodium sulfite and sodium hydroxide were purchased from Shanghai Runjie Chemical Reagent Co, Ltd., China. Oxygen was purchased from Guangzhou Shengying Gas Co, Ltd., Guangdong Province, China.

\subsection{EFB SCMP Preparation}

EFB SCMP sulfonation pretreatment was carried out by laboratory horizontal rotary cooker (KRK 2611, Japan). The sodium sulfite dosage, sodium hydroxide dosage, maximum temperature and cooking time were $18 \mathrm{wt} \%, 4 \mathrm{wt} \%, 155^{\circ} \mathrm{C}$ and $100 \mathrm{~min}$, respectively. The sulfonated materials were subjected to a mechanical pulping process under atmospheric pressure and room temperature with a continuous high-consistency disc refiner (BR30300C; Kumagai Riki Kogyo, Tokyo, Japan) to obtain EFB SCMP. The obtained pulp was collected by sieving through an 80-mesh flat screen for the next processing.

\subsection{Acid Pretreatment}

The obtained EFB SCMP was acid pretreated before ozone treatment in order to improve the selectivity of ozone reaction [23]. Two hundred grams of EFB SCMP (dry weight) was accurately weighed, and the consistency of EFB SCMP was adjusted to $10 \%$ in a polyethylene plastic bag. Sulfuric acid $(2 \mathrm{~mol} / \mathrm{L})$ was added into the bag, and the $\mathrm{pH}$ of EFB SCMP was adjusted to 2.5. The plastic bag was put into a $60{ }^{\circ} \mathrm{C}$ water bath for $60 \mathrm{~min}$ (the bag was rubbed every $15 \mathrm{~min}$ ).

\subsection{Ozone Treatment}

Fifty grams (dry weight) of the acid-treated pulp was taken into the laboratory-made rotary reactor. Ozone gas generated by an ozone generator (ATLAS 60, Stockholm, Sweden) was introduced into the reactor at a fixed concentration and flow rate $(100 \mathrm{mg} / \mathrm{L}, 1 \mathrm{~L} / \mathrm{min})$. The response time was controlled as 5, 15, 25, and 35 min so that the ozone consumption was 1, 3, 5, and $7 \mathrm{wt} \%$, respectively. After the reaction, the exhaust gas was absorbed by the KI solution. The reacted pulp samples were washed with distilled water until $\mathrm{pH}$ reached neutral. All samples were stored at $4{ }^{\circ} \mathrm{C}$ for further analysis.

\subsection{Pulp Refining and Handsheet Making}

The PFI mill is the most commonly used laboratory refiner. It is a high-energy and low-intensity refining device [24]. Untreated and ozone-treated materials were prepared 
for PFI refining from 0 to $4000 \mathrm{r}$ in increments of 1000 reach time to study the effect of different ozone dosage treatments on refining performance. Another group of samples was refined to a refining degree of $43 \pm 2{ }^{\circ} \mathrm{SR}$ for handsheet preparation. In addition, the handsheets were produced in accordance with ISO 5269-2 standard (2004).

\subsection{Characterization}

\subsubsection{XPS Measurements}

The surface of fiber samples was analyzed using X-ray photoelectron spectroscopy (XPS, Kratos Axis Ultra DLD, Manchester, UK). Before the XPS analysis, certain amounts of untreated samples and ozone-treated samples were placed into the Soxhlet and extracted for $4 \mathrm{~h}$ with acetone; extractions on the fiber surface were removed as much as possible after extraction with acetone. Then, the sample was taken out and air-dried enough to be tested. Test conditions were as follows: The monochromatic Al Ka source (Mono Alka) had an energy of $1486.8 \mathrm{eV}, 15 \mathrm{KV} \times 5 \mathrm{~mA}$. Spectra were collected at the energy of $160 \mathrm{eV}$ for full spectrum scan and $40 \mathrm{eV}$ for narrow spectrum scan. The vacuum of the analysis chamber was approximately $5 \times 10^{-9}$ torr. Beam spot size was $700 \times 300 \mu \mathrm{m}$. Scan mode was CAE. The surface coverage of lignin of the samples $\left(\varphi_{\text {Lignin }}\right)$ was calculated according to the following equation [25]:

$$
\varphi_{\text {Lignin }}=\frac{(\mathrm{O} / \mathrm{C})_{\text {sample }}-(\mathrm{O} / \mathrm{C})_{\text {carbohydrate }}}{(\mathrm{O} / \mathrm{C})_{\text {lignin }}-(\mathrm{O} / \mathrm{C})_{\text {carbohydrate }}}
$$

where $(\mathrm{O} / \mathrm{C})_{\text {sample }}$ is the $\mathrm{O} / \mathrm{C}$ ratio of the analyzed samples after extraction, $(\mathrm{O} / \mathrm{C})_{\text {carbohydrate }}$ is the measured $\mathrm{O} / \mathrm{C}$ value of the carbohydrate $(0.83)$ and $(\mathrm{O} / \mathrm{C})_{\text {lignin }}$ is the measured $\mathrm{O} / \mathrm{C}$ value of the lignin model (0.33).

\subsubsection{ATR-FTIR Analysis}

The control and ozone-treated pulps were evaluated using FTIR spectroscopy (VERTEX 70, Bruker, Germany), and the ATR-FTIR spectra were obtained from 4000 to $550 \mathrm{~cm}^{-1}$ with a resolution of $1 \mathrm{~cm}^{-1}$ in the absorbance mode. All the samples were dried in a vacuum drying oven at $40^{\circ} \mathrm{C}$ for $48 \mathrm{~h}$ to remove residual moisture before testing.

\subsubsection{TGA Measurements}

The thermal stability was analyzed by a thermogravimetric analyzer (SDT Q600, TA Instruments, USA). Ten milligrams of sample was taken into the aluminum crucible of the thermogravimetric analyzer to obtain the spectrum. The temperature range was scanned from 30 to $700{ }^{\circ} \mathrm{C}$ at the rate of $10{ }^{\circ} \mathrm{C} / \mathrm{min}$ in a nitrogen atmosphere. The nitrogen flow rate was $25 \mathrm{~mL} / \mathrm{min}$.

\subsubsection{Scanning Electron Microscope}

The surface micromorphology of original and ozone-treated pulp was observed by scanning electron microscope (SEM, EVO 18, Germany Carl Zeiss, Jena, Germany) at an operating voltage of $15 \mathrm{kV}$. Before the observation, samples were fixed on a clean copper plate after freeze-drying by conductive plastic. In order to improve the conductivity of the fiber so that it could be seen more clearly, all samples were sprayed with gold by an ion sputtering coating machine.

\subsubsection{Handsheet Property Measurement}

All prepared handsheets were stored in a constant temperature $\left(23^{\circ} \mathrm{C}\right)$ and humidity (about 50\% RH) environment for $24 \mathrm{~h}$. Basic paper properties of basis weight, thickness and brightness were measured. The physical properties were also measured, such as bursting strength as per ISO 2758 (2014), tearing strength as per ISO 1974 (2012) and tensile strength as per ISO 1924-2 (2008). 


\section{Results and Discussion}

\subsection{Effects on Fiber Surface Chemical Composition}

The control and ozone-treated EFB SCMP fibers were analyzed by XPS. Figure 2a shows typical XPS survey spectra for all samples. The $\mathrm{O} / \mathrm{C}$ radio and surface lignin content (SLC) of different samples are shown in Table 1. Acetone extraction removed most of the extractives in the pulp; therefore, the $\mathrm{O} / \mathrm{C}$ ratio values can be used to describe the concentration of carbohydrate and lignin on the fiber surface [26]. From Table 1, we can see that the $\mathrm{O} / \mathrm{C}$ ratio has a trend of increasing with the intensity of ozone treatment from 0.42 (control) to $0.55(7 \mathrm{wt} \%)$. This means that the fibers have a higher cellulose concentration on the surface after ozone treatment [14]. This may be caused by the degradation of lignin and hemicellulose [27]. Meanwhile, the surface lignin content of fibers could be calculated by the $\mathrm{O} / \mathrm{C}$ ratio value using Equation (1). The analysis of the data listed in Table 1 shows that, compared with the control sample, the ozone-treated samples show some decrease in the concentrations of surface lignin from $82.05 \%$ (control) to $56.81 \%$ (7 wt $\%$ ). The reason may be that some of the lignin on the fiber surface was removed.
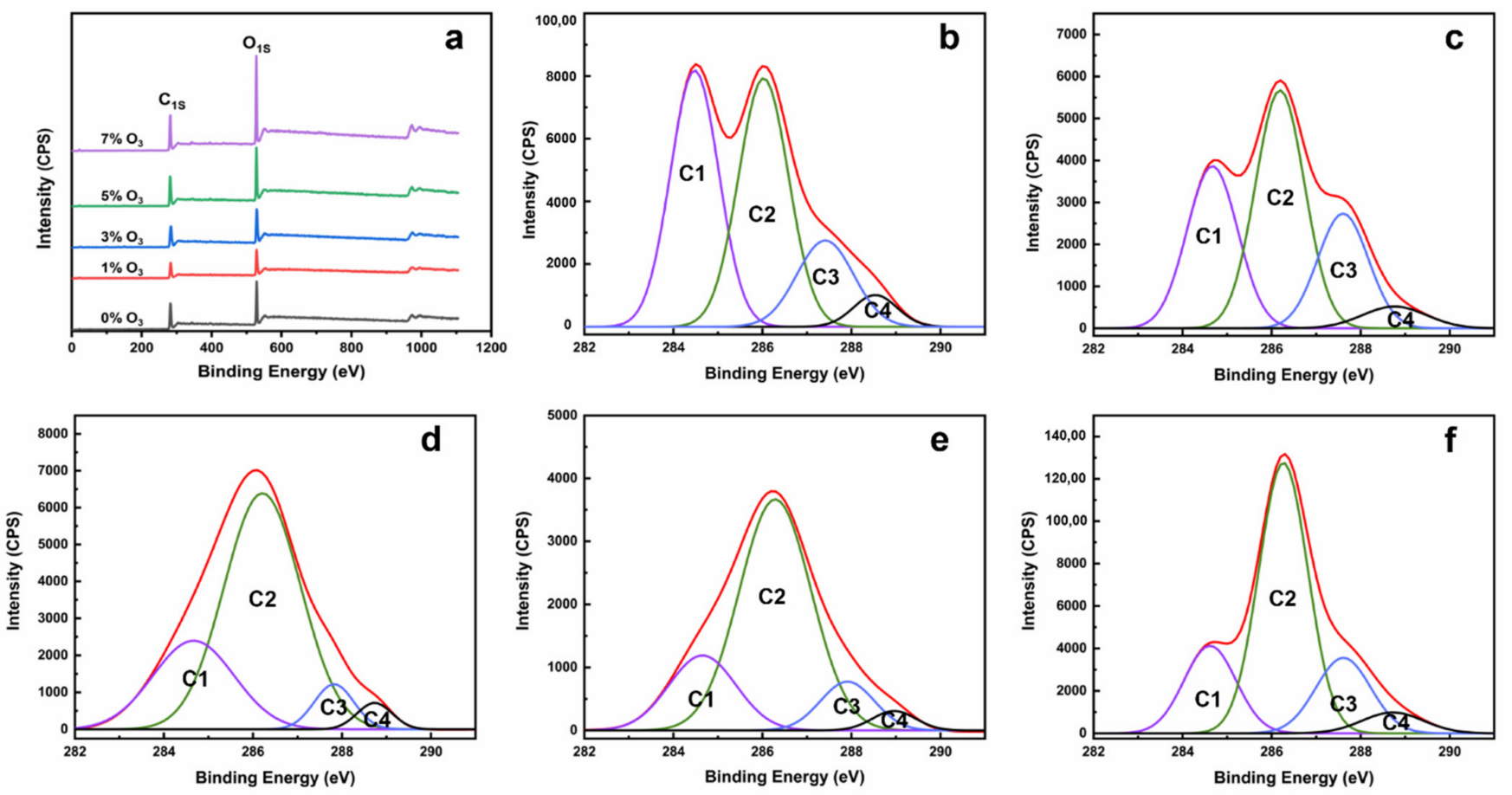

Figure 2. Survey spectra of samples treated with different ozone dosage (a); C1s spectra of untreated and ozone-treated EFB SCMP fibers ((b-f) 013,5 and $7 \mathrm{wt} \%$, respectively).

Table 1. Surface lignin content of fibers treated with different ozone dosages.

\begin{tabular}{ccccc}
\hline Sample & C $_{\mathbf{1 s}}$ Peak Area (\%) & O $_{\mathbf{1 s}}$ Peak Area (\%) & O/C & $\boldsymbol{\Phi}_{\text {Lignin }}(\mathbf{\%})$ \\
\hline $0 \mathrm{wt} \%$ & 69.21 & 29.26 & 0.42 & 82.05 \\
$1 \mathrm{wt} \%$ & 68.65 & 29.90 & 0.43 & 79.49 \\
$3 \mathrm{wt} \%$ & 67.23 & 29.98 & 0.45 & 77.41 \\
$5 \mathrm{wt} \%$ & 65.57 & 33.86 & 0.52 & 68.81 \\
$7 \mathrm{wt} \%$ & 63.96 & 35.11 & 0.55 & 56.81 \\
\hline
\end{tabular}

High-resolution XPS spectra of C1s level were made to evaluate the surface chemical structure of fibers. The $\mathrm{C} 1 \mathrm{~s}$ peak was fitted into four components according to the corresponding carbon atoms: C1, C2, C3 and C4 [28,29]. Generally, C1 corresponds to C-C and $\mathrm{C}-\mathrm{H}, \mathrm{C} 2$ corresponds to $\mathrm{C}-\mathrm{O}, \mathrm{C} 3$ corresponds to $\mathrm{C}=\mathrm{O}$ and $\mathrm{O}-\mathrm{C}-\mathrm{O}$ and $\mathrm{C} 4$ corresponds to $\mathrm{O}=\mathrm{C}-\mathrm{O}$. As shown in Table 2 with their binding energy, after extractives were removed, 
the $\mathrm{C} 1$ and $\mathrm{C} 4$ could represent lignin, with $\mathrm{C} 2$ and $\mathrm{C} 3$ existing in carbohydrate [30,31]. The high-resolution XPS spectra of C1s of untreated and ozone-treated EFB SCMP fibers are shown in Figure $2 \mathrm{~b}-\mathrm{f}$. It was shown that the contribution of the $\mathrm{C} 1$ component of fibers decreased strongly after ozone treatment, from $39.77 \%$ (control) to $19.58 \%$ (7 wt $\%$ ). This trend was consistent with the change of surface lignin, which indicated that lignin was degraded upon ozone treatment. Additionally, the relative amount of C2 increased from $40.01 \%$ (control) to $57.28 \%$ (7 wt\%). The increase in carbohydrate content could be attributed to the preferential degradation of lignin. The content of $\mathrm{C} 1$ and $\mathrm{C} 2$ grades on the fiber surface indicated that they have lower content of lignin and higher content of carbohydrate after the ozone treatment. These results illustrated that more lignin on the fiber surface was dissolved during the ozone treatment, which plays an important role in fiber performance.

Table 2. Classification of carbon the peak components (C1s) for wood fibers.

\begin{tabular}{cccc}
\hline Carbon Atom & Binding Energy (eV) & Carbon & $\begin{array}{c}\text { Main Component } \\
\text { (after Extraction) }\end{array}$ \\
\hline C1 & 284.6 & C-C, C-H & Lignin \\
C2 & $286.1 \pm 0.2$ & C-O & Carbohydrate \\
C3 & $287.6 \pm 0.2$ & C $=\mathrm{O}, \mathrm{O}-\mathrm{C}-\mathrm{O}$ & Carbohydrate \\
C 4 & $288.7 \pm 0.2$ & O-C $=\mathrm{O}$ & Carboxylic acids \\
\hline
\end{tabular}

\subsection{Changes in Functional Groups in Pulps}

Figure 3 shows the FT-IR spectra of control and different ozone dosage treated EFB SCMP fibers. We can see all spectra have strong absorbances at $3348 \mathrm{~cm}^{-1}$, which represents the $\mathrm{O}-\mathrm{H}$ stretching vibration of cellulose and hemicellulose. In addition, there was a strong absorbance at $2910 \mathrm{~cm}^{-1}$, which represents C-H stretching vibration. At $1594-1609 \mathrm{~cm}^{-1}$, the aromatic vibration disappeared, and the absorbance of $\mathrm{C}=\mathrm{O}$ stretch of the conjugated para-substituted aryl ketone increased [32]. This indicated that lignin was destroyed by ozone, which led to the break of aromatic rings and the generation of carboxyl groups. The absorbance at $1590 \mathrm{~cm}^{-1}$ ( $\mathrm{C}=\mathrm{O}$ stretching and aromatic vibration) was shifted to $1635 \mathrm{~cm}^{-1}$ ( $\mathrm{C}=\mathrm{C}$ stretching) after ozone treatment. This phenomenon could be due to the increase in carbonyl groups and condensation of the remaining aromatic structures on the surface of EFB SCMP fibers. Another significant difference in the FT-IR spectra was at $1510 \mathrm{~cm}^{-1}$, which is assigned to the aromatic skeleton vibrations in lignin [33]. Compared with the control sample, the absorbance peak in the ozone-treated spectra was no longer observed here, indicating that the aromatic rings of lignin were reduced. Moreover, the peaks observed at $1247 \mathrm{~cm}^{-1}$ (C-O stretching) shows a tendency to weaken after ozone treatment. This indicated that some lignin and hemicellulose in the fibers were removed by ozone [34]. The FT-IR analysis of control and different ozone dosage treated EFB SCMP fibers showed that carbonyl groups increased and the absorbance of aromatics decreased; the above changes show strong proof that the ozone-lignin reaction degraded the surface lignin of the fibers. 


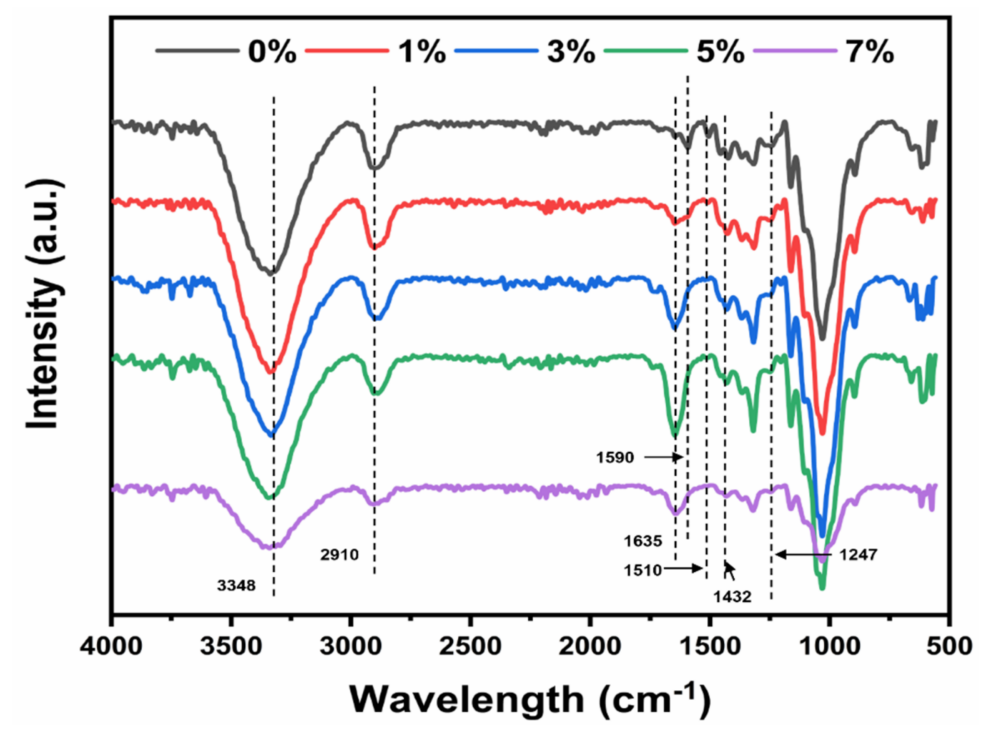

Figure 3. FT-IR spectra of EFB SCMP treated with different ozone dosages.

\subsection{Effect on Fiber Surface Morphology}

To further understand the influence of ozone treatment on pulp fibers, SEM was used to observe the surface morphology of the fibers. It can be observed in Figure $4 \mathrm{a}$ that the surface of the unozonized fiber was smooth, unbroken and uniform. This was because the fiber separation in the chemical-mechanical pulping process mainly occurs in the intercellular layer where the highest lignin content of the fiber in the raw material is; therefore, the surface of the fiber was covered with a large amount of lignin after pulping [35]. However, the large content of lignin on the fiber surface has a negative effect on the subsequent paper properties. In order to obtain high-performance paper, this is what needs to be removed in the pulping process. Figure $4 b-e$ shows the fiber surface treated with different dosages of ozone; compared with untreated fibers, the fiber surface becomes rough and distorted after ozone treatment. Additionally, the primary wall and secondary wall begin to fall off, and many ravines or bulges appear; the greater the amount of ozone, the more obvious this phenomenon.

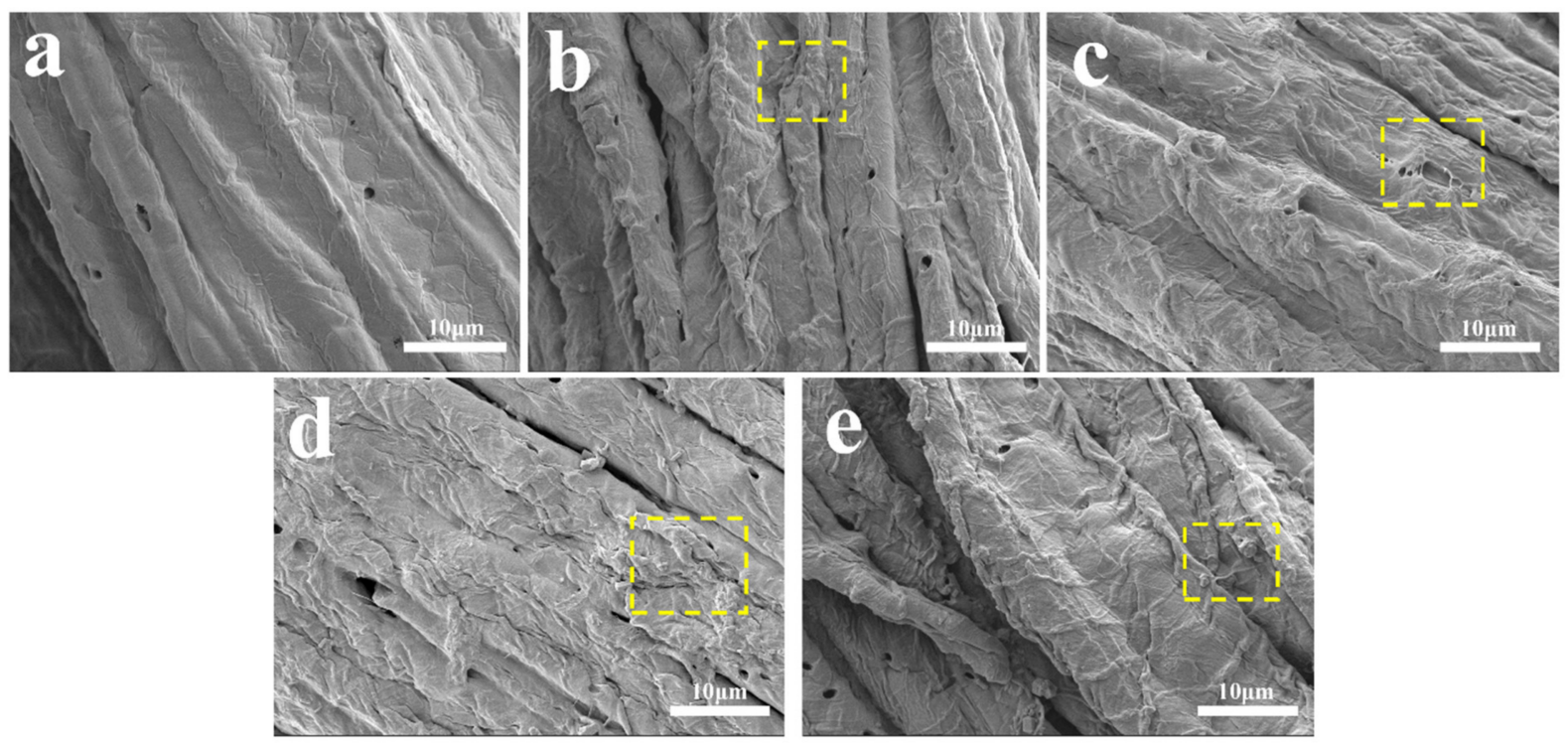

Figure 4. SEM images of EFB SCMP treated with different ozone dosages. ((a-e) $0,1,3,5$ and 7 wt $\%$ ozone dosage, respectively). 


\subsection{Effects on Fiber Thermal Stability}

In this part, we mainly compared and analyzed the fiber thermal stability. Figure 5 presents the TG and DTG curves for the control and treated samples. It can be observed in the TG curves that the quality of the pulp dropped slightly before $200{ }^{\circ} \mathrm{C}$ due to the evaporation of moisture in the fiber [36]. The mass loss of the pulp mainly occurs in the temperature range of 200 to $370{ }^{\circ} \mathrm{C}$, where the main stage of pulp pyrolysis occurs [37]. In addition, we can find that the TG curves shift slightly to the left with the increase in the intensity of ozone treatment. This shows that as the ozone dosage increases, the initial weight loss temperature point of the pulp decreases, from $250{ }^{\circ} \mathrm{C}$ (control) to $180^{\circ} \mathrm{C}(7 \mathrm{wt} \%$ ). Meanwhile, in the control and ozone-treated EFB SCMP DTG curves, the maximum weight loss peak temperature occurs around $330^{\circ} \mathrm{C}$, which corresponds to the temperature of cellulose decomposition [32]. With the increase in ozone dosage, the maximum weight loss peak temperature of the pulp decreased, from $360.5^{\circ} \mathrm{C}$ (control) to $305.2{ }^{\circ} \mathrm{C}(7 \mathrm{wt} \%)$. The reason for these phenomena may be that the separation of lignin and hemicellulose in the pulp leads to hemicellulose decomposition at a lower temperature. The residual weight after the completion of thermal weight loss gradually increased from $13.74 \%$ (control) to $20.27 \%(7 \mathrm{wt} \%)$. This phenomenon may be due to a large amount of lignin and part of the cellulose being removed by the extensive ozone treatment, resulting in an increase in the proportion of non-thermally degradable components in the pulp compared with the untreated samples.
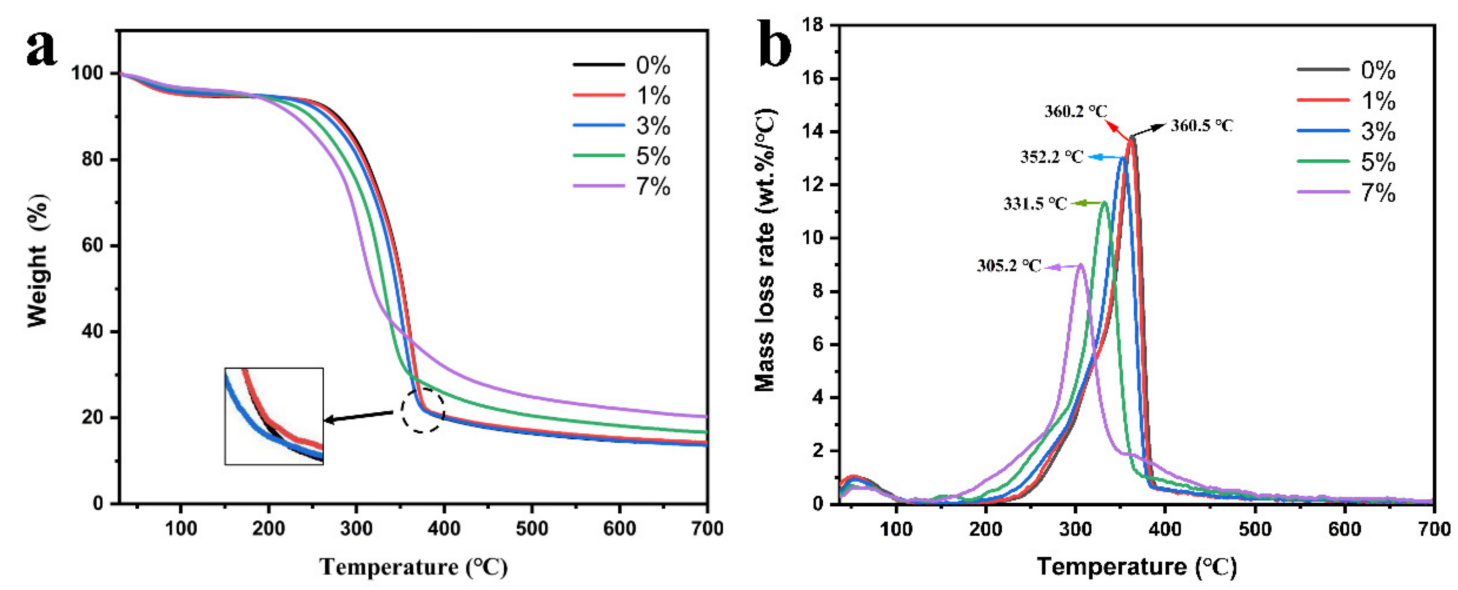

Figure 5. (a) TG and (b) DTG curves of EFB SCMP with different ozone dosage treatments.

\subsection{Effects on Refining Characteristics of Pulp}

The pulp refining process is a mechanical treatment of fibers for improvement of the fiber quality, which can affect the fiber structure and its properties through some simultaneous changes [38]. The principal aim in refining is to make the fiber fibrillate, and thus improve the bonding between fibers in paper [39]. The refining process produces internal fibrillation which can make the fiber more flexible or conformable [40]. It has a great influence on the physical and optical properties of pulp and paper, including paper formation and paper strength.

Table 3 shows the refining degree changes in PFI refining. We can see from the data in the table that as the amount of ozone increases, the initial refining degree of the pulp increases. The initial refining degree of EFB SCMP pulp without ozone treatment was $19.4^{\circ} \mathrm{SR}$, which increased to $22.0^{\circ} \mathrm{SR}$ when the ozone dosage was increased to $7 \mathrm{wt} \%$, an increase of $13.4 \%$. Moreover, with the continuous increase in refining revolutions, the refining degree of ozone-treated pulp was always increasing, and the increase was relatively higher than that of untreated pulp. This could be explained by ozone reacting with the lignin on the fiber surface, which decreases the lignin content in pulp and plays a similar role in mechanical refining. When papermaking needs to achieve a standard 
refining degree, the ozone-treated pulp requires fewer refining revolutions, which means that more refining energy consumption could be saved, thus resulting in cost savings.

Table 3. The effect of different ozone dosages on refining performance of EFB SCMP.

\begin{tabular}{cccccc}
\hline Ozone Dosage & $\mathbf{0 ~ r}$ & $\mathbf{1 0 0 0} \mathbf{r}$ & $\mathbf{2 0 0 0} \mathbf{r}$ & $\mathbf{3 0 0 0} \mathbf{~ r}$ & $\mathbf{4 0 0 0} \mathbf{~ r}$ \\
\hline $0 \mathrm{wt} \%$ & $19.4^{\circ} \mathrm{SR}$ & $36.0^{\circ} \mathrm{SR}$ & $46.0^{\circ} \mathrm{SR}$ & $51.4^{\circ} \mathrm{SR}$ & $58.0^{\circ} \mathrm{SR}$ \\
$1 \mathrm{wt} \%$ & $19.8^{\circ} \mathrm{SR}$ & $37.0^{\circ} \mathrm{SR}$ & $46.4^{\circ} \mathrm{SR}$ & $52.1^{\circ} \mathrm{SR}$ & $60.3^{\circ} \mathrm{SR}$ \\
$3 \mathrm{wt} \%$ & $20.0^{\circ} \mathrm{SR}$ & $37.5^{\circ} \mathrm{SR}$ & $47.0^{\circ} \mathrm{SR}$ & $52.5^{\circ} \mathrm{SR}$ & $61.1^{\circ} \mathrm{SR}$ \\
$5 \mathrm{wt} \%$ & $21.5^{\circ} \mathrm{SR}$ & $40.0^{\circ} \mathrm{SR}$ & $48.5^{\circ} \mathrm{SR}$ & $57.0^{\circ} \mathrm{SR}$ & $63.2^{\circ} \mathrm{SR}$ \\
$7 \mathrm{wt} \%$ & $22.0^{\circ} \mathrm{SR}$ & $40.5^{\circ} \mathrm{SR}$ & $51.0^{\circ} \mathrm{SR}$ & $59.0^{\circ} \mathrm{SR}$ & $64.0^{\circ} \mathrm{SR}$ \\
\hline
\end{tabular}

\subsection{Effects on Handsheets' Physical Properties}

The physical properties of handsheets produced by treating EFB SCMP with different ozone dosages were studied, including brightness, tightness, bursting index, tensile index, tearing index and zero tensile index.

The brightness and tightness are shown in Figure 6a. The brightness of paper increased from $41.5 \%$ ISO to $46.8 \%$ ISO with the ozone treatment. The increase in brightness was attributed to the removal of lignin by ozone. The paper tightness increased first and then decreased with the increase in ozone consumption. When the ozone dosage was $3 \mathrm{wt} \%$, the tightness reached a maximum of $0.66 \mathrm{~cm}^{3} / \mathrm{g}$, which was an increase of $18.09 \%$ compared with control $\left(0.56 \mathrm{~cm}^{3} / \mathrm{g}\right)$. High tightness means that the fibers are softer, which would be beneficial for the handsheets' physical properties.
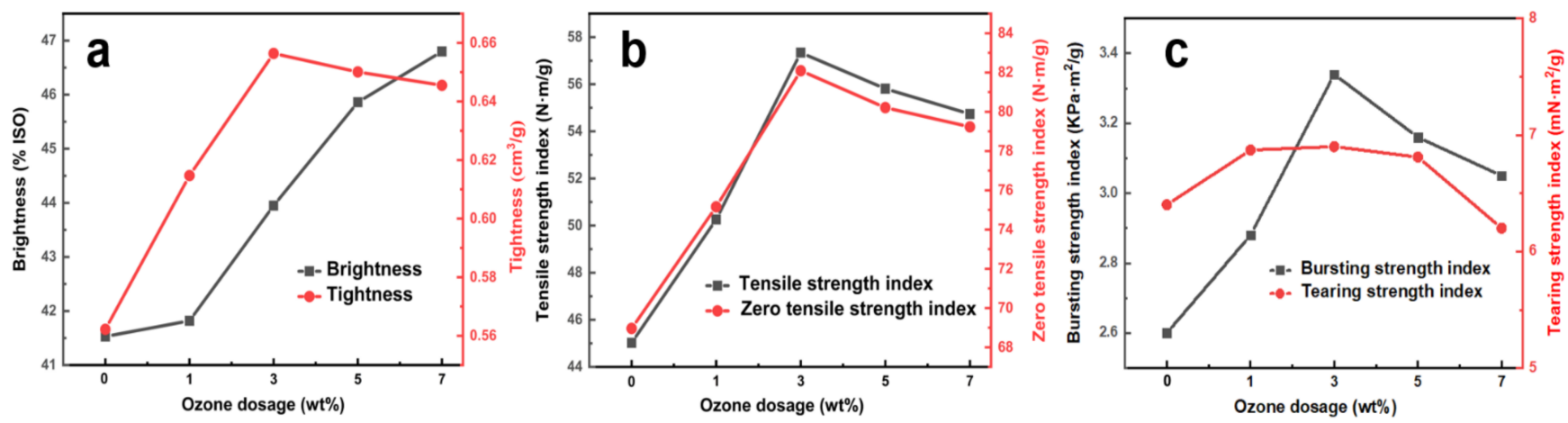

Figure 6. Influence of ozone treatment on physical strength of handsheets: (a) brightness and tightness variation; (b) tensile strength index and zero tensile strength index variation; (c) bursting strength index and tearing strength index variation.

The bond strength between fibers is one of the main factors that control the physical strength of paper [41]. As reported, the lignin on the fiber surface affects the bond between the fibers, and the removal of even a small amount of lignin from the fiber surface can significantly improve the bond between fibers [35]. As discussed previously, XPS and FTIR analyses of EFB SCMP fibers show that the surface lignin content was decreased after ozone treatment, so the effect on handsheets' physical properties can be explained.

Tensile strength is one of the most important physical properties, and zero tensile strength is a recognized physical performance index first proposed by Hoffman-Jacobsen to measure the strength of the fiber itself [42]. The curves in Figure $6 \mathrm{~b}$ exhibit the changes of tensile strength and zero tensile strength with ozone treatment. It can be seen that both tensile and zero tensile strength indexes show the same trend, increasing first to reach the maximum value at $3 \mathrm{wt} \% \mathrm{O}_{3}$. Compared with untreated samples, they increased by $27.37 \%$ and $19.04 \%$, respectively, and then decreased slightly. The phenomenon may be due to most of the lignin on the fiber surface being removed with the continuous increase in the amount of ozone, exposing more cellulose and hemicellulose and allowing the ozone to react with the cellulose easily, which affected the strength of the fibers. 
The bursting strength and tearing strength variations are shown in Figure 6c. The bursting strength index of handsheets exhibits a change similar to that of tensile strength. The maximum value was $3.34 \mathrm{kPa} \cdot \mathrm{m}^{2} / \mathrm{g}(3 \mathrm{wt} \%)$, increasing by $28.46 \%$ when compared with untreated samples. Likewise, the tearing strength showed a trend of slowly rising first, up to $6.9 \mathrm{mN} \cdot \mathrm{m}^{2} / \mathrm{g}(3 \mathrm{wt} \%)$, and then decreasing. The main factors affecting the tearing strength are the average length and the bonding force of the fibers. When the ozone treatment occurred at a low dosage, the ozone mainly reacted with the surface lignin; therefore, the fiber length was not affected, and the bonding force between the fibers was enhanced, so the tearing strength improved before $3 \mathrm{wt} \%$ ozone consumption. As the previous analyses show, ozone reacted with the cellulose when the amount of ozone was too high, reducing fiber length and, inevitably, decreasing the tearing strength index of the handsheets.

\section{Conclusions}

In this study, we used ozone treatment to improve the performance of EFB SCMP. The effect of different ozone dosage treatments on the performance of EFB SCMP was deeply investigated. XPS and FTIR characterization results showed that part of the lignin structure was disrupted and removed; the surface lignin content was reduced from 82.05 to $56.81 \%$ when the ozone dosage increased to $7 \mathrm{wt} \%$. Besides, the SEM results show that many ravines or bulges appeared on the fiber surface after ozone treatment. The PFI refining results showed that the ozone-treated pulp was more easily fibrillated and lower refining energy consumption was needed. Meanwhile, the physical properties of handsheets were improved after ozone treatment, and the tensile index, zero tensile index, burst index and tear index of ozone-treated pulp increased by $27.37 \%, 19.04 \%, 28.46 \%$ and $7.8 \%$, respectively, with $3 \mathrm{wt} \% \mathrm{O}_{3}$ consumption.

This work using oil palm empty fruit bunches from the palm oil industry as raw materials to produce pulp will not only relieve the pressure on the paper industry due to the scarcity of wood materials but also make good use of waste materials. In addition, ozone as a clean and efficient oxidation reagent can improve pulp performance due to the selective lignin removal ability. The above results confirm that ozone treatment is an effective, environmentally friendly and low-cost treatment method to improve the comprehensive properties of the EFB SCMP.

Author Contributions: Conceptualization, X.W. and J.L.; methodology, X.W., Y.P. and J.L.; validation, X.W. and Y.P.; experiments, X.W. and Y.P.; formal analysis, X.W., Y.P. and J.L.; resources, J.L.; data curation, X.W. and Y.P.; writing—original draft preparation, X.W.; writing-review and editing, X.W., Y.P. and J.L.; visualization, J.L.; supervision, J.L. All authors have read and agreed to the published version of the manuscript.

Funding: This research received no external funding.

Data Availability Statement: Data are contained within the article or supplemented upon request from the section editors.

Acknowledgments: The authors thank the Guangzhou Science and Technology Plan Projects (201707020011), the Special Support Plan for High Level Talent Cultivation of Guangdong Province (No. 2014TQ01N603), the State Key Laboratory of Pulp and Paper Engineering (201831), and Guangdong Province Science Foundation for Cultivating National Engineering Research Center for Efficient Utilization of Plant Fibers (2017B090903003).

Conflicts of Interest: The authors declare no conflict of interest.

\section{References}

1. Zhang, X.; Li, J.; Gong, J.; Kuang, Y.; He, S.; Xu, J.; Mo, L.; Man, Y.; Zhu, W.; Song, J. Cleaner approach for medium con-sistency eucalyptus slab pulp production using ozone bleaching under turbulent mixing. J. Clean. Prod. 2020, 276, 124201. [CrossRef]

2. Jaunky, V.C.; Lundmark, R. Dynamics of Wood Pulp Production: Evidence from OECD Countries. Forests 2017, 8, 107. [CrossRef]

3. Kaur, D.; Bhardwaj, N.K.; Lohchab, R.K. A study on pulping of rice straw and impact of incorporation of chlorine dioxide during bleaching on pulp properties and effluents characteristics. J. Clean. Prod. 2018, 170, 174-182. [CrossRef] 
4. Sharma, A.K.; Anupam, K.; Swaroop, V.; Lal, P.S.; Bist, V. Pilot scale soda-anthraquinone pulping of palm oil empty fruit bunches and elemental chlorine free bleaching of resulting pulp. J. Clean. Prod. 2015, 106, 422-429. [CrossRef]

5. Khalil, H.P.S.A.; Fazita, M.R.N.; Bhat, A.H.; Jawaid, M.; Fuad, N.A.N. Development and material properties of new hybrid plywood from oil palm biomass. Mater. Des. 2010, 31, 417-424. [CrossRef]

6. Liu, K.; Lyu, P.; Ping, Y.; Hu, Z.; Mo, L.; Li, J. Chemical-free thermomechanical pulping of empty fruit bunch and sugarcane bagasse. BioResources 2019, 14, 8627-8639.

7. Zhang, H.; He, Z.; Ni, Y. Improvement of high-yield pulp properties by using a small amount of bleached wheat straw pulp. Bioresour. Technol. 2011, 102, 2829-2833. [CrossRef]

8. Xu, E.; Wang, D.; Lin, L. Chemical Structure and Mechanical Properties of Wood Cell Walls Treated with Acid and Alkali Solution. Forests 2020, 11, 87. [CrossRef]

9. Ferraz, A.; Guerra, A.; Mendonça, R.; Masarin, F.; Vicentim, M.P.; Aguiar, A.; Pavan, P.C. Technological advances and mechanistic basis for fungal biopulping. Enzyme Microb. Technol. 2008, 43, 178-185. [CrossRef]

10. Lei, X.; Zhao, Y.; Li, K.; Pelletier, A. Improved surface properties of CTMP fibers with enzymatic pretreatment of wood chips prior to refining. Cellulose 2012, 19, 2205-2215. [CrossRef]

11. Mulyantara, L.T.; Harsono, H.; Maryana, R.; Jin, G.; Das, A.K.; Ohi, H. Properties of thermomechanical pulps derived from sugarcane bagasse and oil palm empty fruit bunches. Ind. Crops Prod. 2017, 98, 139-145. [CrossRef]

12. Hu, G.; Fu, S.; Liu, H.; Lucia, L.A. Adsorption of cationized eucalyptus heteropolysaccharides onto chemical and mechanical pulp fibers. Carbohydr. Polym. 2015, 123, 324-330. [CrossRef] [PubMed]

13. Franzeiz, R. General and selective upgrading of mechanical pulps. Nord. Pulp Pap. Res. J. 1986, 1, 4-13. [CrossRef]

14. Liu, Y.; Liu, M.; Li, H.; Li, B.; Zhang, C. Characteristics of high yield pulp fibers by xylanase treatment. Cellulose 2016, 23, 3281-3289. [CrossRef]

15. Liao, J.; He, S.; Mo, L.; Guo, S.; Luan, P.; Zhang, X.; Li, J. Mass-production of high-yield and high-strength thermomechanical pulp fibers from plant residues enabled by ozone pretreatment. J. Clean. Prod. 2021, 296, 126575. [CrossRef]

16. Shatalov, A.A.; Pereira, H. Arundo donax L. reed: New perspectives for pulping and bleaching. 5. Ozone-based TCF bleaching of organosolv pulps. Bioresour. Technol. 2008, 99, 472-478. [CrossRef]

17. Maqsood, H.S.; Bashir, U.; Wiener, J.; Puchalski, M.; Sztajnowski, S.; Militky, J. Ozone treatment of jute fibers. Cellulose 2017, 24, 1543-1553. [CrossRef]

18. Tripathi, S.K.; Bhardwaj, N.K.; Roy Ghatak, H. Developments in ozone-based bleaching of pulps. Ozone Sci. Eng. 2020, 42, 194-210. [CrossRef]

19. Souza-Corrêa, J.A.; Ridenti, M.A.; Oliveira, C.; Araújo, S.R.; Amorim, J. Decomposition of lignin from sugar cane bagasse during ozonation process monitored by optical and mass spectrometries. J. Phys. Chem. B 2013, 117, 3110-3119. [CrossRef]

20. Gilli, E.; Schmied, F.; Diebald, S.; Horvath, A.T.; Teichert, C.; Schennach, R. Analysis of lignin precipitates on ozone treated kraft pulp by FTIR and AFM. Cellulose 2012, 19, 249-256. [CrossRef]

21. Mamleeva, N.A.; Autlov, S.A.; Fionov, A.V.; Bazarnova, N.G.; Lunin, V. V The oxidative destruction of lignin in the ozo-nation of wood. Russ. J. Phys. Chem. A 2009, 83, 745-751.

22. Bajpai, P. Biotechnology for Pulp and Paper Processing; Springer: Berlin/Heidelberg, Germany, 2012; ISBN 1461414083.

23. Roncero, M.B.; Queral, M.A.; Colom, J.F.; Vidal, T. Why Acid pH Increases the Selectivity of the Ozone Bleaching Processes. Ozone Sci. Eng. 2003, 25, 523-534. [CrossRef]

24. Kerekes, R.J. Characterizing refining action in PFI mills. Tappi J. 2005, 4, 9-13.

25. Chandra, R.P.; Chu, Q.; Hu, J.; Zhong, N.; Lin, M.; Lee, J.-S.; Saddler, J. The influence of lignin on steam pretreatment and mechanical pulping of poplar to achieve high sugar recovery and ease of enzymatic hydrolysis. Bioresour. Technol. 2016, 199, 135-141. [CrossRef] [PubMed]

26. Johansson, L.-S.; Campbell, J.M.; Koljonen, K.; Stenius, P. Evaluation of surface lignin on cellulose fibers with XPS. Appl. Surf. Sci. 1999, 144, 92-95. [CrossRef]

27. Clark, T.A.; Steward, D.; Bruce, M.E.; McDonald, A.G.; Singh, A.P.; Senior, D.J. Improvement bleachability of radiata pine kraft pulps following treatment with hemicellulolytic enzymes. Appita J. 1991, 44, 389-404.

28. Sinn, G.; Reiterer, A.; Stanzl-Tschegg, S.E. Surface analysis of different wood species using X-ray photoelectron spectroscopy (XPS). J. Mater. Sci. 2001, 36, 4673-4680. [CrossRef]

29. Wang, S.; Jämsä, S.; Mahlberg, R.; Ihalainen, P.; Nikkola, J.; Mannila, J.; Ritschkoff, A.-C.; Peltonen, J. Treatments of paper surfaces with sol-gel coatings for laminated plywood. Appl. Surf. Sci. 2014, 288, 295-303. [CrossRef]

30. Bouafif, H.; Koubaa, A.; Perré, P.; Cloutier, A.; Riedl, B. Analysis of among-species variability in wood fiber surface using DRIFTS and XPS: Effects on esterification efficiency. J. Wood Chem. Technol. 2008, 28, 296-315. [CrossRef]

31. Doris, G.M.; Gray, D.G. The surface analysis of paper and wood fibers by ESCA. I. Cellul. Chem. Technol. 1978, 12, 9-23.

32. Bule, M.V.; Gao, A.H.; Hiscox, B.; Chen, S. Structural modification of lignin and characterization of pretreated wheat straw by ozonation. J. Agric. Food Chem. 2013, 61, 3916-3925. [CrossRef]

33. Migneault, S.; Koubaa, A.; Perré, P.; Riedl, B. Effects of wood fiber surface chemistry on strength of wood-plastic composites. Appl. Surf. Sci. 2015, 343, 11-18. [CrossRef]

34. Shanmugasundaram, N.; Rajendran, I.; Ramkumar, T. Characterization of untreated and alkali treated new cellulosic fiber from an Areca palm leaf stalk as potential reinforcement in polymer composites. Carbohydr. Polym. 2018, 195, 566-575. 
35. Shao, Z.; Li, K. The effect of fiber surface lignin on interfiber bonding. J. Wood Chem. Technol. 2006, 26, 231-244. [CrossRef]

36. Mayandi, K.; Rajini, N.; Pitchipoo, P.; Winowlin Jappes, J.T.; Varada Rajulu, A. Properties of Untreated and Chemically Treated Cissus Quadrangularis Natural Fibers and Their Composites with Polyester as the Matrix. Polym. Compos. 2018, 39, 876-886. [CrossRef]

37. Yang, Y.; Li, T.; Jin, S.; Lin, Y.; Yang, H. Catalytic pyrolysis of tobacco rob: Kinetic study and fuel gas produced. Bioresour. Technol. 2011, 102, 11027-11033. [CrossRef]

38. Gharehkhani, S.; Sadeghinezhad, E.; Kazi, S.N.; Yarmand, H.; Badarudin, A.; Safaei, M.R.; Zubir, M.N.M. Basic effects of pulp refining on fiber properties-A review. Carbohydr. Polym. 2015, 115, 785-803. [CrossRef]

39. Zukeri, M.R.H.M.; Ghazali, A.; Lazin, M.A.K.M. Morphological and mechanical effects of extended beating on EFB pulp web. AIP Conf. Proc. 2012, 1482, 268-272.

40. Genco, J.M. Fundamental processes in stock preparation and refining. In Proceedings of the Tappi Pulping Conference, Orlando, FL, USA, 31 October-4 November 1999; pp. 57-96.

41. Page, D.H. A theory for the tensile strength of paper. Tappi 1969, 52, 674-681.

42. Li, K.; Reeve, D.W. The origins of kraft pulp fiber surface lignin. J. Pulp Pap. Sci. 2002, 28, 369-373. 